\title{
PES- $\mathrm{Ag}_{3} \mathrm{PO}_{4} / \mathrm{g}-\mathrm{C}_{3} \mathrm{~N}_{4}$ Mixed Matrix Film Photocatalyst for Degradation of Methyl Orange Dye
}

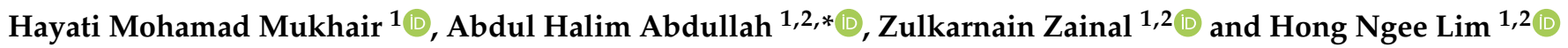 \\ 1 Institute of Advanced Technology, Universiti Putra Malaysia, Serdang 43400, Selangor, Malaysia; \\ hayatimukhair@gmail.com (H.M.M.); zulkar@upm.edu.my (Z.Z.); hongngee@upm.edu.my (H.N.L.) \\ 2 Department of Chemistry, Faculty of Science, Universiti Putra Malaysia, Serdang 43400, Selangor, Malaysia \\ * Correspondence: halim@upm.edu.my
}

check for updates

Citation: Mukhair, H.M.; Abdullah, A.H.; Zainal, Z.; Lim, H.N.

PES- $\mathrm{Ag}_{3} \mathrm{PO}_{4} / \mathrm{g}-\mathrm{C}_{3} \mathrm{~N}_{4}$ Mixed Matrix Film Photocatalyst for Degradation of Methyl Orange Dye. Polymers 2021, 13, 1746. https://doi.org/10.3390/ polym 13111746

Academic Editor: Loris Pietrelli

Received: 27 February 2021

Accepted: 15 April 2021

Published: 27 May 2021

Publisher's Note: MDPI stays neutral with regard to jurisdictional claims in published maps and institutional affiliations.

Copyright: (c) 2021 by the authors. Licensee MDPI, Basel, Switzerland. This article is an open access article distributed under the terms and conditions of the Creative Commons Attribution (CC BY) license (https:/ / creativecommons.org/licenses/by/ $4.0 /)$.

\begin{abstract}
In the present study, we explored the effectiveness of PES- $\mathrm{Ag}_{3} \mathrm{PO}_{4} / \mathrm{g}-\mathrm{C}_{3} \mathrm{~N}_{4}$ film photocatalyst in degrading methyl orange dye under visible light irradiation. The PES- $\mathrm{Ag}_{3} \mathrm{PO}_{4} / \mathrm{g}-\mathrm{C}_{3} \mathrm{~N}_{4}$ film photocatalyst was prepared via a non-solvent-induced phase inversion process and characterized by X-ray diffraction (XRD), scanning electron microscopy (SEM), laser scanning microscopy (LSM), X-ray photoelectron spectra (XPS), UV-diffuse reflectance (DRS), and water contact angle. The incorporation of the $\mathrm{Ag}_{3} \mathrm{PO}_{4} / \mathrm{g}-\mathrm{C}_{3} \mathrm{~N}_{4}$ composite into the PES matrix improved the pristine PES film's hydrophilicity, as evidenced by the reduction of water contact angle from $79.03^{\circ}$ to $54.33^{\circ}$ for a film containing $15 \mathrm{wt} \%$ of $\mathrm{Ag}_{3} \mathrm{PO}_{4} / \mathrm{g}-\mathrm{C}_{3} \mathrm{~N}_{4}$ composite. The film's photoactivity showed that $13 \mathrm{wt} \%$ was the best loading of $\mathrm{Ag}_{3} \mathrm{PO}_{4} / \mathrm{g}-\mathrm{C}_{3} \mathrm{~N}_{4}$ composite, and the degradation performance was maintained up to three cycles. The $\bullet \mathrm{O}_{2}{ }^{-}$and $\mathrm{h}^{+}$were the predominant species responsible for the methyl orange degradation.
\end{abstract}

Keywords: film photocatalyst; $\mathrm{PES}-\mathrm{Ag}_{3} \mathrm{PO}_{4} / \mathrm{g}-\mathrm{C}_{3} \mathrm{~N}_{4}$; visible light photocatalyst; wastewater treatment; methyl orange; $\mathrm{Ag}_{3} \mathrm{PO}_{4}$

\section{Introduction}

Textile industries wastewater contains many types of dyes and chemical substances that pose an environmental challenge in wastewater disposal issues. Dye substances are toxic toward microorganisms, and their intense color blocks sunlight from penetrating the water, which causes severe problems for the aquatic ecosystem. Azo dyes, the largest group of synthetic colorants, are usually used in the textile industry. These dyes possess high stability against light, temperature, chemicals, and microbial attack, making conventional wastewater treatment less efficient. Moreover, the use of traditional physical and chemical methods produces secondary pollutants [1].

Advanced oxidation processes (AOPs) are the technologies that generally use hydroxyl radicals, the ultimate oxidant for remediating organic contaminants in wastewater by converting recalcitrant pollutants into biodegradable compounds. The efficacy of AOPs depends on the generation of reactive free radicals, mainly the hydroxyl radicals. The most favorable AOPs in wastewater treatment include Fenton oxidation [2], catalytic ozonation [3], and semiconductor-based heterogeneous photocatalysis.

In the past decades, heterogenous photocatalysis using transition metal oxides as catalysts stood out as a promising candidate in treatment methods because of its low cost and environmentally benign properties. Photocatalysis could mineralize organic compounds directly under solar irradiation and under mild conditions of temperature and pressure. However, the photocatalysts available to date are generally limited by either low photocatalytic efficiency in the visible light range or insufficient charge separation ability [4].

Recently, much effort is focused on the exploration of visible light active semiconductor photocatalysts. Silver phosphate, $\mathrm{Ag}_{3} \mathrm{PO}_{4}$, has been reported to possess superior 
photooxidative capabilities for the degradation of organic dyes under visible light irradiation. However, self-photo corrosion is the main limitation of $\mathrm{Ag}_{3} \mathrm{PO}_{4}$, which restricts its application for only one cycle. Coupling $\mathrm{Ag}_{3} \mathrm{PO}_{4}$ with graphitic carbon nitride $\left(\mathrm{g}-\mathrm{C}_{3} \mathrm{~N}_{4}\right)$ is one of the promising techniques to suppress photo-corrosion and effectively enhance photocatalytic performance [5-7]. g- $\mathrm{C}_{3} \mathrm{~N}_{4}$ is known as a metal-free semiconductor (bandgap energy is $2.7 \mathrm{eV}$ ) with a $\pi$-conjugated structure and possesses high standard reduction potential $(-1.15 \mathrm{eV}$ vs. normal hydrogen electrode (NHE)) to produce more oxygen oxidation species (e.g., hydroxyl radical) [5]. The excellent photocatalytic activity of $\mathrm{Ag}_{3} \mathrm{PO}_{4} / \mathrm{g}-\mathrm{C}_{3} \mathrm{~N}_{4}$ composite is ascribed to the efficient electron-hole separation [8].

Another major problem that restricts photocatalyst application in wastewater treatment is post-treatment difficulty after the degradation process. The powder form photocatalyst undergoes severe agglomeration, and its recovery is challenging, which leads to a high separation operation cost. By immobilizing the photocatalyst into a polymer matrix, such a problem can be overcome. Several polymers have successfully been used as supports for photocatalysts, which includes polyamide, polyvinylidene fluoride (PVDF) [9-11], polysulfone (PS) [12,13], polyethersulfone (PES) [14,15], polyurethane (PU) [16,17], and polyacrylonitrile (PAN) [18-20].

Lately, PES gains more attention due to its resistance toward UV irradiation and hydroxyl radicals produced in the photocatalytic reaction, thus making it a suitable support material for photocatalysts [21-23]. However, most of the studies focused on UV active photocatalyst incorporated into PES matrix as film photocatalyst. To the best of our knowledge, incorporating visible light photocatalyst into PES has not been studied, mainly in the photocatalysis process. Herein, this study focuses on using immobilized $\mathrm{Ag}_{3} \mathrm{PO}_{4} / \mathrm{g}-\mathrm{C}_{3} \mathrm{~N}_{4}$ PES photocatalyst film in the degradation of methyl orange dye. The effects of operational parameters include composite loadings, initial pollutant concentration, initial $\mathrm{pH}$, and film thickness, were investigated.

\section{Materials and Methods}

\subsection{Materials}

Polyethersulfone (PES Ultrason E6020P with $\mathrm{M}_{\mathrm{W}}=75,000 \mathrm{~g} / \mathrm{mol}$ ) was purchased from Solvay Specialty Polymers, (Jurong Island, Singapore). Thiourea $\left(\mathrm{CH}_{4} \mathrm{~N}_{2} \mathrm{~S}\right)$ was purchased from HmbG (Kuala Lumpur, Malaysia). N-methyl-2-pyrolidone (NMP) and silver nitrate $\left(\mathrm{AgNO}_{3}\right)$ were purchased from Merck, di-sodium hydrogen phosphate $\left(\mathrm{Na}_{2} \mathrm{HPO}_{4}\right)$ was purchased from Sigma Aldrich (Petaling Jaya, Malaysia), and methyl orange (MO) was purchased from Bendosen Laboratory Chemicals (Kuala Lumpur, Malaysia). Distilled water was used throughout the study. All chemicals are of analytical grade and were used without any further purification.

\section{2. $\mathrm{Ag}_{3} \mathrm{PO}_{4} / g-\mathrm{C}_{3} \mathrm{~N}_{4}$ Photocatalyst Preparation}

In a typical synthesis of graphitic carbon nitride $\left(\mathrm{g}-\mathrm{C}_{3} \mathrm{~N}_{4}\right), 5 \mathrm{~g}$ of thiourea was heated in a muffle furnace at $500{ }^{\circ} \mathrm{C}$ for $2 \mathrm{~h}$. The resulting yellow powder was washed via sonication in distilled water for $2 \mathrm{~h}$ and oven-dried at $60^{\circ} \mathrm{C}$ overnight. The $\mathrm{Ag}_{3} \mathrm{PO}_{4} / \mathrm{g}-\mathrm{C}_{3} \mathrm{~N}_{4}$ composite photocatalysts were fabricated by the facile co-precipitation method. Generally, $100 \mathrm{~mL}$ of $0.6 \mathrm{M}$ of $\mathrm{AgNO}_{3}$ was added into $100 \mathrm{~mL}$ of distilled water, containing $0.1 \mathrm{~g}$ of dispersed $\mathrm{g}-\mathrm{C}_{3} \mathrm{~N}_{4}$ powder, and stirred for $1 \mathrm{~h}$. Then, $100 \mathrm{~mL}$ of $0.25 \mathrm{M} \mathrm{Na}_{2} \mathrm{HPO}_{4}$ was added dropwise into the suspended solution and stirred for $2 \mathrm{~h}$. The obtained product was collected and washed with distilled water and ethanol before being dried overnight at $60^{\circ} \mathrm{C}$.

\section{3. $\mathrm{PES} / \mathrm{Ag}_{3} \mathrm{PO}_{4}-\mathrm{g}-\mathrm{C}_{3} \mathrm{~N}_{4}(\mathrm{P}-\mathrm{AgC})$ Composite Film Preparation}

$\mathrm{P}-\mathrm{AgC}$ was prepared by a previously reported methodology [14]. A certain amount of $\mathrm{Ag}_{3} \mathrm{PO}_{4} / \mathrm{g}-\mathrm{C}_{3} \mathrm{~N}_{4}$ powder was added into the clear PES casting solution, which was prepared by dissolving a fixed amount of PES flakes in the organic solvent (NMP) and stirred at $60^{\circ} \mathrm{C}$ for $24 \mathrm{~h}$ to uniformly dispersed the $\mathrm{Ag}_{3} \mathrm{PO}_{4} / \mathrm{g}-\mathrm{C}_{3} \mathrm{~N}_{4}$ in the PES solution. The compositions of the prepared film are tabulated in Table 1 . The solution mixture was 
cast on a glass plate $(10 \mathrm{~cm} \times 8 \mathrm{~cm})$ using a casting knife with a gap setting of $100 \mu \mathrm{m}$. The glass plate was immersed in a nonsolvent media (distilled water) and stored in the dark for a day for the solvent-nonsolvent demixing process and separated the film from the glass. Lastly, the resulting films were air-dried at room temperature for $24 \mathrm{~h}$ and ready to be used in photocatalytic studies.

Table 1. The casting solution compositions for the preparation of $\mathrm{P}-\mathrm{Ag}_{3} \mathrm{PO}_{4} / g-\mathrm{C}_{3} \mathrm{~N}_{4}$ film photocatalyst.

\begin{tabular}{cccc}
\hline PES (wt \%) & $\left.\mathbf{A g}_{3} \mathbf{P O}_{\mathbf{4}} / \mathbf{g}-\mathbf{C}_{\mathbf{3}} \mathbf{N}_{\mathbf{4}} \mathbf{( w t} \%\right)$ & NMP $\mathbf{~} \mathbf{w t} \%)$ & Label \\
\hline 15 & 0 & 85 & PES \\
15 & 9 & 76 & P-AgC $(9 \%)$ \\
15 & 11 & 74 & P-AgC $(11 \%)$ \\
15 & 13 & 72 & P-AgC $(13 \%)$ \\
15 & 15 & 70 & P-AgC $(15 \%)$ \\
\hline
\end{tabular}

\section{4. $\mathrm{PES} / \mathrm{Ag}_{3} \mathrm{PO}_{4}-\mathrm{g}-\mathrm{C}_{3} \mathrm{~N}_{4}(\mathrm{P}-\mathrm{AgC})$ Composite Film Characterization}

The crystallinity and phase formation of the PES and PES- $\mathrm{Ag}_{3} \mathrm{PO}_{4} / \mathrm{g}-\mathrm{C}_{3} \mathrm{~N}_{4}$ film photocatalysts were analyzed using an X-ray diffractometer (PHILIPS PW 3040/60, Almelo, Netherlands) with $\mathrm{CuK} \alpha$ radiation $(\lambda=0.154 \mathrm{~nm}, 30 \mathrm{kV}, 30 \mathrm{~mA})$ in the scan range of $2 \theta=10^{\circ}$ to $80^{\circ}$ with a $2^{\circ} / \mathrm{min}$ of scanning speed. The surface film's morphology was observed using a scanning electron microscope equipped with an electron dispersive X-ray analyzer (Fei Nova Nanosem 230, Eindhoven, Holland). Meanwhile, the cross-section film morphology was visualized by a scanning electron microscope equipped with an electron dispersive X-ray analyzer (SEM-EDX, HITACHI TM3000, Tokyo, Japan. A 3D measuring laser microscope (OLS5000 OLYMPUS, Hamburg, Germany) was used to capture the film's surface roughness. The X-ray photoelectron spectra (XPS) of the prepared samples were recorded using a Kratos Analytical Axis Ultra DLD photoelectron spectrometer (Manchester, UK) using an $\mathrm{Al} \mathrm{K} \alpha$ radiation monochromatic source. The water contact angle of the film was analyzed by a water surface analysis system (VCA 3000S, Billerica, MA, USA).

\subsection{Photocatalytic Studies}

The photocatalytic activities of the photocatalyst were evaluated by degradation of methyl orange (MO), a model pollutant, under visible light irradiation The photodegradation was conducted in a $0.5 \mathrm{~L}$ glass photoreactor, as shown in Figure 1. Two pieces of P-AgC film photocatalyst $(10 \mathrm{~cm} \times 8 \mathrm{~cm})$ were placed around the photoreactor. A known concentration of $\mathrm{MO}$ solution $(0.3 \mathrm{~L})$ was introduced into the photoreactor. Air was bubbled into the solution to ensure continuous oxygen supply. The film was put under dark condition for $20 \mathrm{~min}$ to achieve adsorption-desorption equilibrium before being irradiated by $23 \mathrm{~W}$ (fluorescent lamp) for $180 \mathrm{~min}$. Then, $5 \mathrm{~mL}$ of sample was withdrawn from the bulk solution at 30 min time intervals, and the residual concentration of the MO was measured using a UV-vis spectrophotometer (Perkin Elmer Lambda 35, Waltham, USA) at $\lambda_{\max }=465.4 \mathrm{~nm}$. The degradation efficiency and the amount of MO degraded were determined using Equations (1) and (2), respectively.

$$
\begin{gathered}
\text { Degradation Efficiency }(\%)=\frac{C_{o}-C_{t}}{C_{o}} \times 100 \% \\
\text { Amount of MO degraded }(\mathrm{mg} / \mathrm{g})=\frac{\left(C_{o}-C_{t}\right) \frac{\mathrm{mg}}{\mathrm{L}} \times \operatorname{volume}(\mathrm{L})}{\text { mass of P-AgC film }(\mathrm{g})}
\end{gathered}
$$

where $C_{o}$ is the concentration of methyl orange (MO) before irradiation and $C_{t}$ is the concentration of $\mathrm{MO}$ at ' $t$ ' time. 


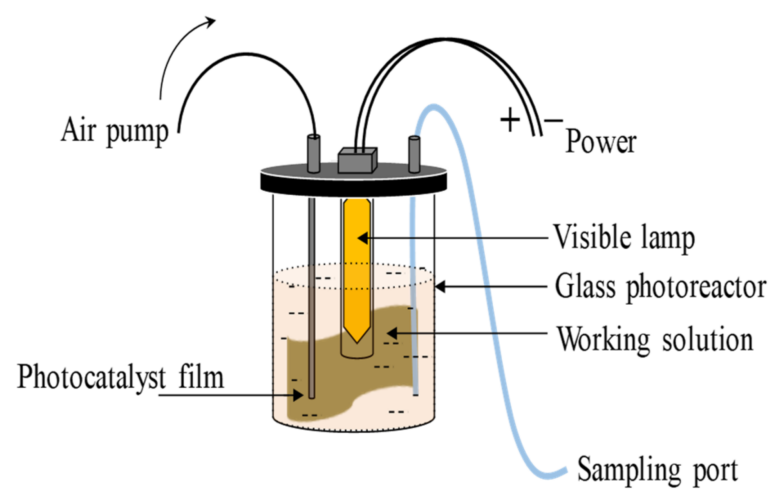

Figure 1. Schematic representation of the photocatalytic reactor setup for photocatalytic activity in a static mode.

Chemical oxygen demand (COD) analysis was performed by digesting $2 \mathrm{~mL}$ of $\mathrm{MO}$ in a fixed amount of the oxidant reagent (Lovibond) at $150{ }^{\circ} \mathrm{C}$ for $1 \mathrm{~h}$ by using Thermoreactor RD125 (Lovibond). A colorimeter (DR/890) was used to read the COD concentration. The COD percentage was calculated according to the equation as follows:

$$
\text { COD percentage }(\%)=\frac{\mathrm{COD}_{o}-\mathrm{COD}_{t}}{\mathrm{COD}_{o}} \times 100 \%
$$

where $\mathrm{COD}_{o}$ and $\mathrm{COD}_{t}$ are the $\mathrm{COD}$ concentration initially and at a time " $t$ ", respectively.

\section{Results and Discussion}

\subsection{Characterization of P-AgC Composite Films}

The X-ray diffraction patterns of net PES, powder $\mathrm{Ag}_{3} \mathrm{PO}_{4}, \mathrm{~g}-\mathrm{C}_{3} \mathrm{~N}_{4}$, and selected $\mathrm{P}-\mathrm{AgC}$ film photocatalysts are depicted in Figure 2. No peak was observed for bare PES, indicating the amorphous nature of the polymer matrix. The addition of $\mathrm{Ag}_{3} \mathrm{PO}_{4} / \mathrm{g}-\mathrm{C}_{3} \mathrm{~N}_{4}$ into the PES matrix contributed to the appearance of several $\mathrm{Ag}_{3} \mathrm{PO}_{4}$ peaks that was indexed as body-centred cubic phase (JCPDS No. 060505), and no other impurities were observed, indicating that the samples were composed of pure phase $\mathrm{Ag}_{3} \mathrm{PO}_{4}$. No diffraction pattern for $\mathrm{g}-\mathrm{C}_{3} \mathrm{~N}_{4}$ was observed due to the small amount of usage. It can be concluded that there were no Ag particles present in the composite film.

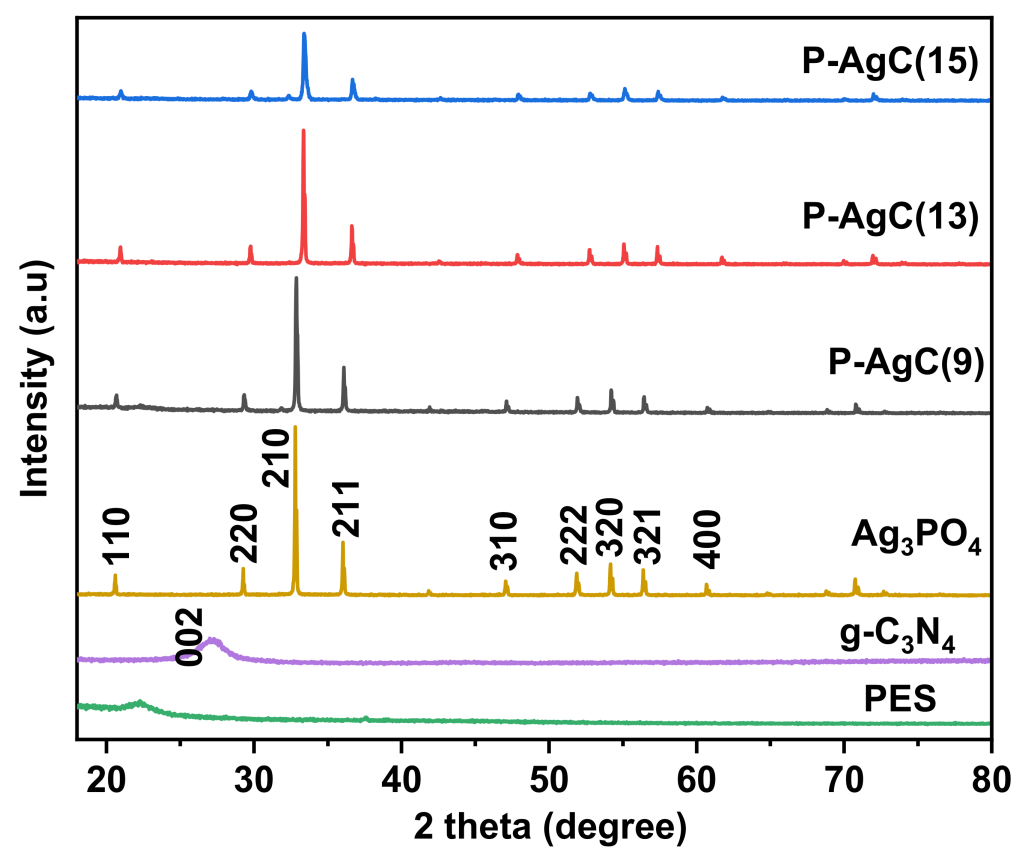

Figure 2. X-ray diffraction patterns of $\mathrm{P}$ - $\mathrm{AgC}$ in different loadings of $\mathrm{Ag}_{3} \mathrm{PO}_{4} / \mathrm{g}-\mathrm{C}_{3} \mathrm{~N}_{4}$ composite. 
The morphology of the PES- $\mathrm{Ag}_{3} \mathrm{PO}_{4} / \mathrm{g}-\mathrm{C}_{3} \mathrm{~N}_{4}$ composite film photocatalyst was observed and depicted in Figure 3. The cross-sectional SEM images well revealed that the PES is made up of a top dense skin layer and finger-like void structures at the bottom layer, which represents asymmetric membranes characteristics. As a result of $\mathrm{Ag}_{3} \mathrm{PO}_{4} / \mathrm{g}-\mathrm{C}_{3} \mathrm{~N}_{4}$ addition, the uniform finger-like microstructures of PES became elongated and non-uniform, with bottle-neck microvoids, appeared at the bottom layer. The presence of the $\mathrm{Ag}_{3} \mathrm{PO}_{4} / \mathrm{g}$ $\mathrm{C}_{3} \mathrm{~N}_{4}$ composite might have enhanced the casting solution instability and accelerated the demixing process, which facilitated the development of non-uniform microvoids in the composite film $[24,25]$. The surface morphology and surface roughness of the composite films are evaluated based on FESEM and LSM images. The smooth surface of the neat PES film becomes rougher with the increased $\mathrm{Ag}_{3} \mathrm{PO}_{4} / g-\mathrm{C}_{3} \mathrm{~N}_{4}$ content. The increase in the average surface roughness may be due to the $\mathrm{Ag}_{3} \mathrm{PO}_{4} / \mathrm{g}-\mathrm{C}_{3} \mathrm{~N}_{4}$ composite aggregation, as shown by the LSM image (Figure 4). The surface hydrophilicity of the films was evaluated by contact angle analysis (Figure 5). By increasing the $\mathrm{Ag}_{3} \mathrm{PO}_{4} / g-\mathrm{C}_{3} \mathrm{~N}_{4}$ composite content in PES membrane, the water contact angle reduced compared to neat PES, indicating that the hydrophilicity of the composite film had improved. The enhanced hydrophilicity can be due to Ag high affinity toward the water and the existence of hydrophilic groups such as $\mathrm{N}-\mathrm{H}$ in $\mathrm{g}-\mathrm{C}_{3} \mathrm{~N}_{4}[24,26]$.

Figure 6 shows the XPS spectra of the as-prepared $\mathrm{Ag}_{3} \mathrm{PO}_{4} / g-\mathrm{C}_{3} \mathrm{~N}_{4}$ composite, which reveals the chemical compositions and chemical states of the samples. From the XPS survey spectra in Figure $6 \mathrm{a}$, the elements of $\mathrm{Ag}, \mathrm{P}, \mathrm{C}, \mathrm{N}$, and $\mathrm{O}$ were detected. Figure $6 \mathrm{~b}$ shows the high-resolution $\mathrm{Ag} 3 \mathrm{~d}$ spectrum and two deconvoluted peaks that ascribe to $\mathrm{Ag}^{+}$in $\mathrm{Ag}_{3} \mathrm{PO}_{4}$ were seen at $373.3 \mathrm{eV}$ and $367.8 \mathrm{eV}$ corresponding to $\mathrm{Ag} 3 \mathrm{~d}_{3 / 2}$ and $\mathrm{Ag} 3 \mathrm{~d}_{5 / 2}$, respectively [5]. The result confirmed that no Ag was formed during the composite preparation. In Figure $6 \mathrm{c}$, the $\mathrm{P} 2 \mathrm{p}$ peak appeared at $132.6 \mathrm{eV}$, suggesting that the phosphorus in the sample existed in the pentavalent oxidation state $\left(\mathrm{P}^{5+}\right)$ [27]. It can be seen from the $\mathrm{C} 1 \mathrm{~s}$ spectrum (Figure $6 \mathrm{~d}$ ) that the curve could be fitted into two peaks located at $284.6 \mathrm{eV}$, corresponding to the C-C bond with sp ${ }^{2}$ orbital, and the peak located at $288.1 \mathrm{eV}$ could be assigned to $\mathrm{CN}_{3}$ bonds in the heterocycle ring of $\mathrm{g}-\mathrm{C}_{3} \mathrm{~N}_{4}[6,28,29]$. The $\mathrm{N} 1_{\mathrm{S}}$ spectrum (Figure $6 \mathrm{e}$ ) can be deconvoluted into four peaks at 298.2,399.7, 401.4, and $403.1 \mathrm{eV}$, which can be attributed to $\mathrm{C}-\mathrm{N}=\mathrm{C}, \mathrm{N}-(\mathrm{C})_{3}, \mathrm{~N}-\mathrm{H}$, and $\mathrm{N}-\mathrm{O}$ in $\mathrm{g}-\mathrm{C}_{3} \mathrm{~N}_{4}$ structure, respectively. The $\mathrm{O} 1 \mathrm{~s}$ peaks (Figure $6 \mathrm{f}$ ) at $530.5 \mathrm{eV}$ and $532.4 \mathrm{eV}$ are associated with the $\mathrm{O}_{2}{ }^{-}$in the $\mathrm{Ag}_{3} \mathrm{PO}_{4}$ and an $-\mathrm{OH}$ group or a water molecule on the surface of the composite.
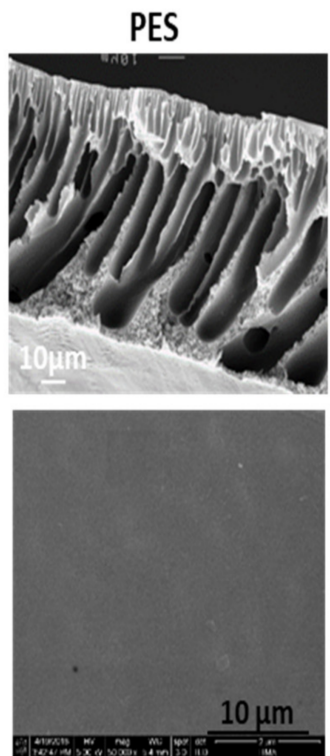
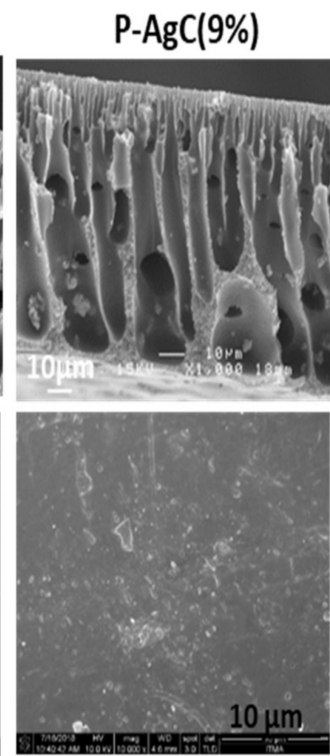
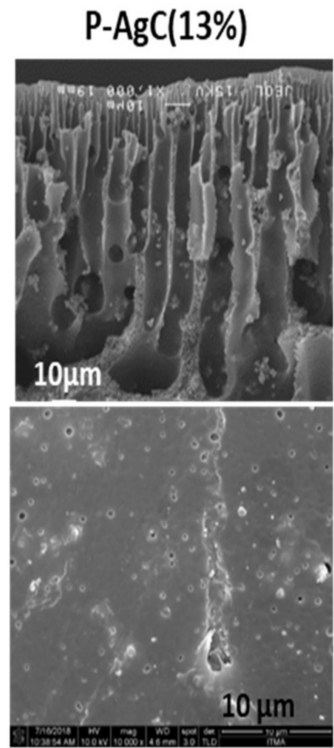

$\operatorname{P}-\operatorname{AgC}(15 \%)$
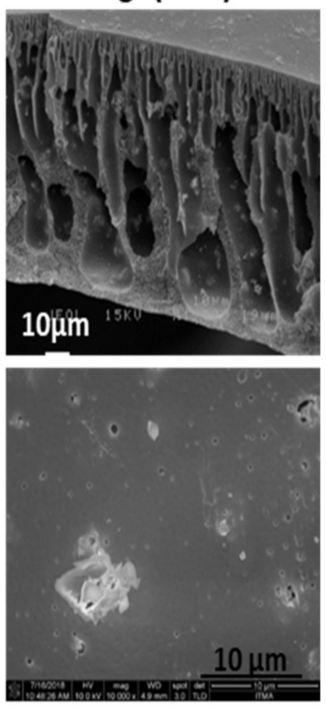

Figure 3. SEM cross-section images and FESEM surface images of PES net, P-AgC (9\%), P-AgC (13\%), and P-AgC (15\%) composite films. 

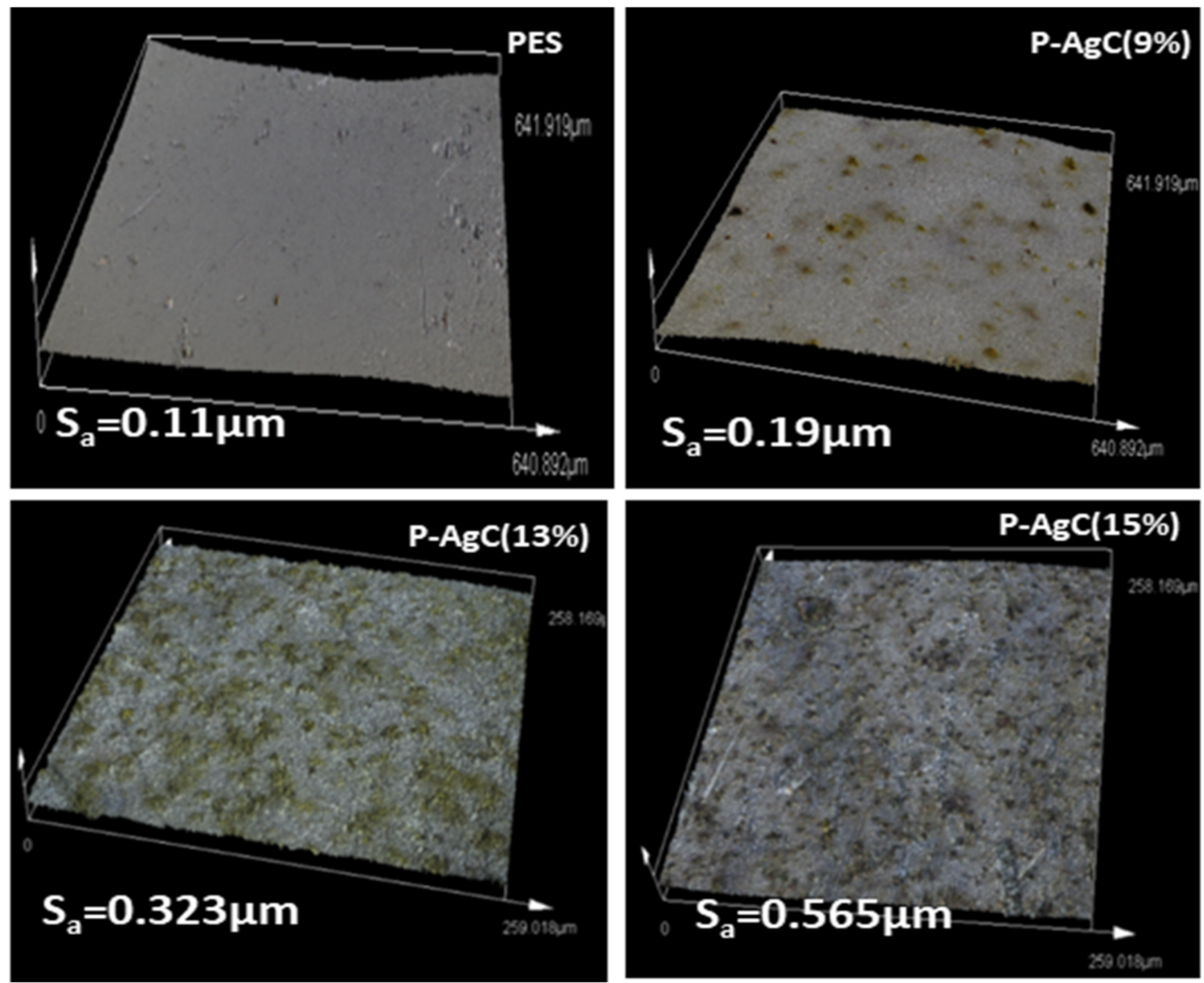

Figure 4. The surface roughness of the neat PES net, P-AgC (9\%), P-AgC (13\%), and P-AgC (15\%) composite films.

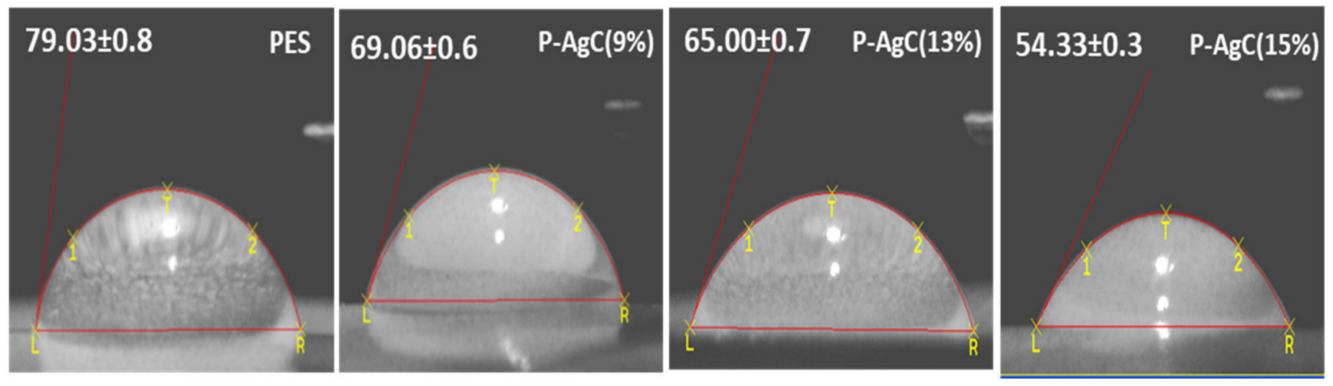

Figure 5. The water contact angle for the neat PES net, P-AgC (9\%), P-AgC (13\%), and P-AgC (15\%) composite films.

The optical properties of the $\mathrm{Ag}_{3} \mathrm{PO}_{4} / \mathrm{g}-\mathrm{C}_{3} \mathrm{~N}_{4}$ composite photocatalyst were measured using UV-vis diffuse reflectant spectroscopy (DRS). As shown in Figure 7a, the absorption edge of pure $\mathrm{Ag}_{3} \mathrm{PO}_{4}$ and $g-\mathrm{C}_{3} \mathrm{~N}_{4}$ were detected at approximately $440 \mathrm{~nm}$ and $550 \mathrm{~nm}$, indicating that both the $\mathrm{Ag}_{3} \mathrm{PO}_{4}$ and g- $\mathrm{C}_{3} \mathrm{~N}_{4}$ can absorb visible light energy. Meanwhile, the light absorption of the $\mathrm{Ag}_{3} \mathrm{PO}_{4} / \mathrm{g}-\mathrm{C}_{3} \mathrm{~N}_{4}$ composite showed two edges and broad background in the visible light region, which means that the visible light absorption ability was improved. Based on the Kubelka-Munk function, the plots of $(\mathrm{Ahv})^{1 / 2} \mathrm{vs.} \mathrm{hv} \mathrm{for}$ $\mathrm{Ag}_{3} \mathrm{PO}_{4}, \mathrm{~g}-\mathrm{C}_{3} \mathrm{~N}_{4}$, and $\mathrm{Ag}_{3} \mathrm{PO}_{4} / \mathrm{g}-\mathrm{C}_{3} \mathrm{~N}_{4}$ composite are shown in Figure $7 \mathrm{~b}$. The indirect bandgap energies of the $\mathrm{Ag}_{3} \mathrm{PO}_{4}$ and $\mathrm{g}-\mathrm{C}_{3} \mathrm{~N}_{4}$ were $2.1 \mathrm{eV}$ and $2.5 \mathrm{eV}$, respectively. For the $\mathrm{Ag}_{3} \mathrm{PO}_{4} / \mathrm{g}-\mathrm{C}_{3} \mathrm{~N}_{4}$ composite, the bandgap for $\mathrm{Ag}_{3} \mathrm{PO}_{4}$ maintained, while the bandgap for g- $\mathrm{C}_{3} \mathrm{~N}_{4}$ reduced to $2.3 \mathrm{eV}$ significantly. 

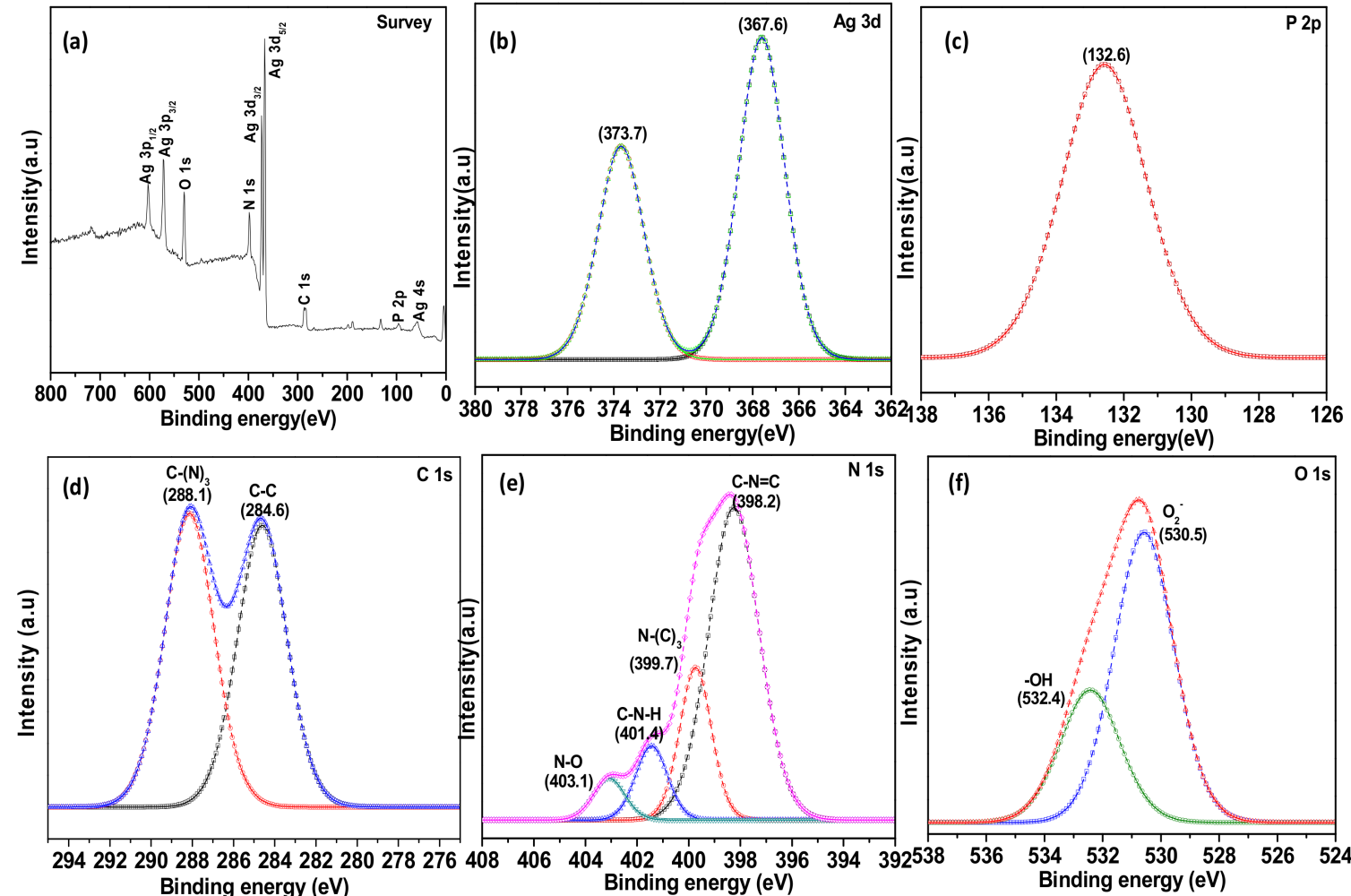

Figure 6. (a) Full XPS spectra and high resolution (b) Ag 3d peak, (c) P 2p peak, (d) C 1s peak, (e) N 1s peak, and (f) O 1s peak of $\mathrm{Ag}_{3} \mathrm{PO}_{4} / \mathrm{g}-\mathrm{C}_{3} \mathrm{~N}_{4}$ composite.
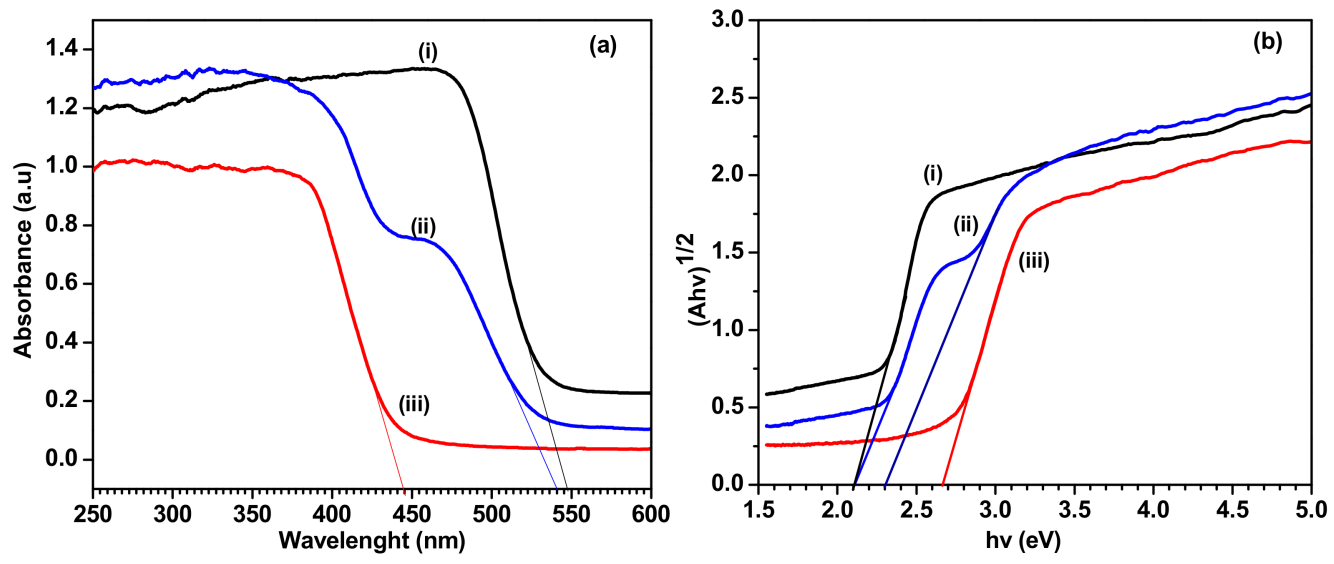

Figure 7. (a) UV-vis diffuse reflectant spectroscopy (DRS) spectra and (b) band gap energy of (i) $\mathrm{Ag}_{3} \mathrm{PO}_{4}$, (ii) $\mathrm{Ag}_{3} \mathrm{PO}_{4} / \mathrm{g}-\mathrm{C}_{3} \mathrm{~N}_{4}$ composite and (iii) $\mathrm{g}-\mathrm{C}_{3} \mathrm{~N}_{4}$.

\subsection{The Photocatalytic Activity of the P-AgC Film Photocatalysts}

The photocatalytic activity of P-AgC film photocatalysts was evaluated by degrading methyl orange (MO) under visible light irradiation. Before the photocatalytic reaction, the sample was immersed in the MO solution for $30 \mathrm{~min}$ in dark to reach the adsorption-desorption equilibrium. Direct photolysis showed no degradation of MO in aqueous solution, which confirmed the stability of $\mathrm{MO}$ under visible light irradiation. The degradation efficiency and degradation rate are shown in Figure 8. Net PES did not show any photocatalytic properties. The degradation efficiency of P-AgC (13\%) was $97 \%$, which resulted in highest degradation efficiency and the rate of reaction among the samples tested (Table 2). It showed that the presence of carbon nitride enhanced the photocatalytic properties of $\mathrm{Ag}_{3} \mathrm{PO}_{4}$. The enhanced photodegradation efficiency could also be attributed 
to the increasing hydrophilicity of the photocatalyst film, as evidenced in Figure 5. The improved surface wettability of the film allows more contact between the $\mathrm{MO}$ and the $\mathrm{Ag}_{3} \mathrm{PO}_{4} / \mathrm{g}-\mathrm{C}_{3} \mathrm{~N}_{4}$ photocatalyst, leading to a higher $\mathrm{MO}$ adsorption on the surface of the photocatalyst film (Figure S1), hence higher photocatalytic efficiency. However, as the $\mathrm{Ag}_{3} \mathrm{PO}_{4} / \mathrm{g}-\mathrm{C}_{3} \mathrm{~N}_{4}$ loadings increased up to $15 \mathrm{wt} \%$, the degradation efficiency decreased. This phenomenon might be due to the agglomeration of $\mathrm{Ag}_{3} \mathrm{PO}_{4} / g-\mathrm{C}_{3} \mathrm{~N}_{4}$ particles in the PES matrix. The agglomeration resulted in lower active surface area of $\mathrm{Ag}_{3} \mathrm{PO}_{4} / \mathrm{g}-\mathrm{C}_{3} \mathrm{~N}_{4}$ for photon absorption to promote photocatalyst activation. Thus, $13 \mathrm{wt} \%$ is the maximum amount of $\mathrm{Ag}_{3} \mathrm{PO}_{4} / \mathrm{g}-\mathrm{C}_{3} \mathrm{~N}_{4}$ that could be immobilized onto the PES film to successfully achieve optimum photocatalytic activity.
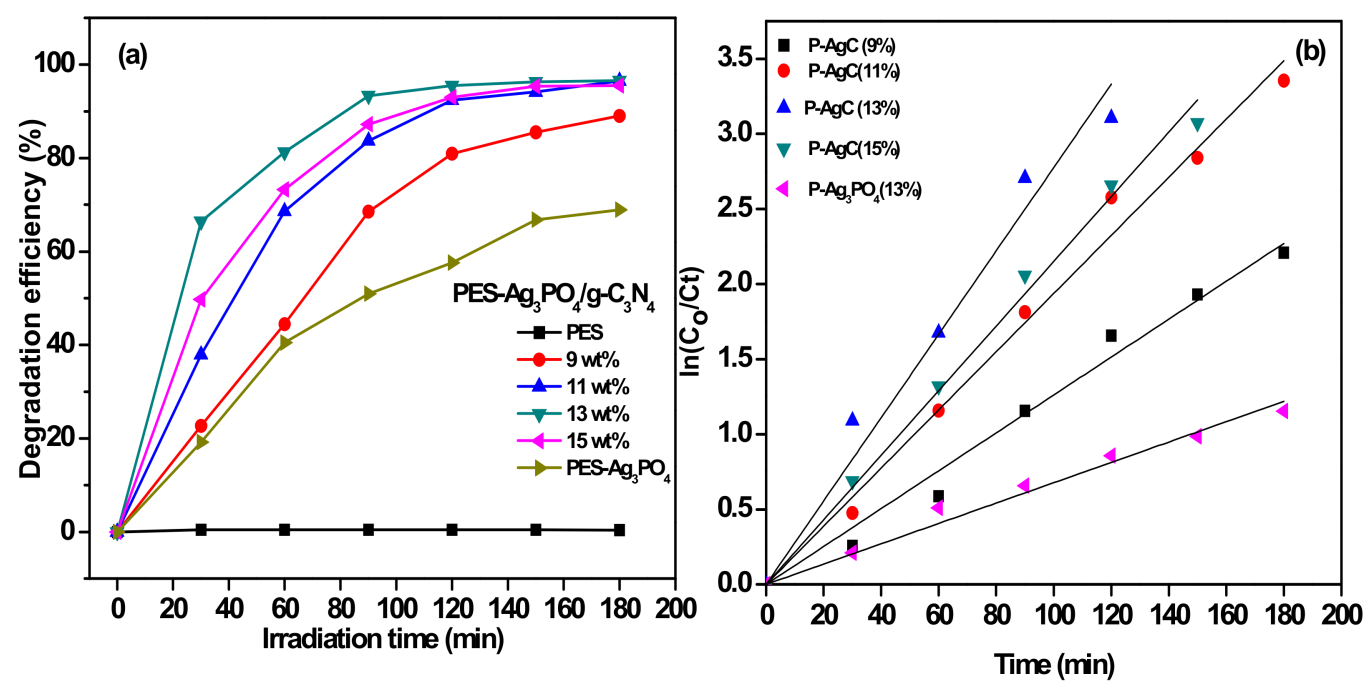

Figure 8. (a) Degradation efficiency and (b) kinetic study of the degradation of MO by the P-AgC photocatalyst films with different $\mathrm{Ag}_{3} \mathrm{PO}_{4} / \mathrm{g}-\mathrm{C}_{3} \mathrm{~N}_{4}$ content (0-15 wt \%) (volume of MO: $0.3 \mathrm{~L}$, number of the film: 2 films, $\mathrm{MO}$ concentration: $10 \mathrm{mg} / \mathrm{L}$ ).

Table 2. Kinetic data and amount of MO degraded by the P-AgC photocatalyst films.

\begin{tabular}{|c|c|c|c|c|}
\hline Sample & $\begin{array}{l}\text { Degradation } \\
\text { Efficiency (\%) }\end{array}$ & $\begin{array}{c}k_{\text {obs }} \\
\left(\min ^{-1}\right)\end{array}$ & $\begin{array}{c}\text { Rate } \\
\text { (mg/Lmin) }\end{array}$ & $\begin{array}{l}\text { Correlation } \\
\text { Factor }\left(\mathbf{R}^{2}\right)\end{array}$ \\
\hline $\mathrm{P}-\mathrm{Ag}_{3} \mathrm{PO}_{4}(13 \%)$ & 68.69 & 0.007 & 0.067 & 0.994 \\
\hline P-AgC (9\%) & 89.01 & 0.013 & 0.126 & 0.994 \\
\hline P-AgC (11\%) & 96.50 & 0.020 & 0.193 & 0.996 \\
\hline P-AgC (13\%) & 96.58 & 0.028 & 0.277 & 0.991 \\
\hline P-AgC (15\%) & 95.50 & 0.022 & 0.215 & 0.998 \\
\hline
\end{tabular}

The effect of MO initial concentration toward degradation efficiency is shown in Figure 9, and details are outlined in Table 3. It was found that the degradation efficiency decreased as the $\mathrm{MO}$ concentration increased due to the screening effect of $\mathrm{MO}$ dye that reduced the path length of the photon that arrived on the surface of the photocatalyst. At low $\mathrm{MO}$ concentration, the number of reactive radicals $\left(\bullet \mathrm{OH}\right.$ and $\left.\bullet \mathrm{O}_{2}{ }^{-}\right)$is more than the number of $\mathrm{MO}$ molecules, increasing the chance of collision between the pollutant and the active site of catalyst. Hence, it increased the tendency of adsorption and oxidation of $\mathrm{MO}$ on the surface of catalyst [30]. As the $\mathrm{MO}$ concentration increased, the adsorption of substrate molecules on the photocatalyst surface suppressed the generation of reactive radicals. Practically, the reaction cannot be enhanced as the amount of active sites and the concentrations of the hydroxyl radicals are constant [31]. 

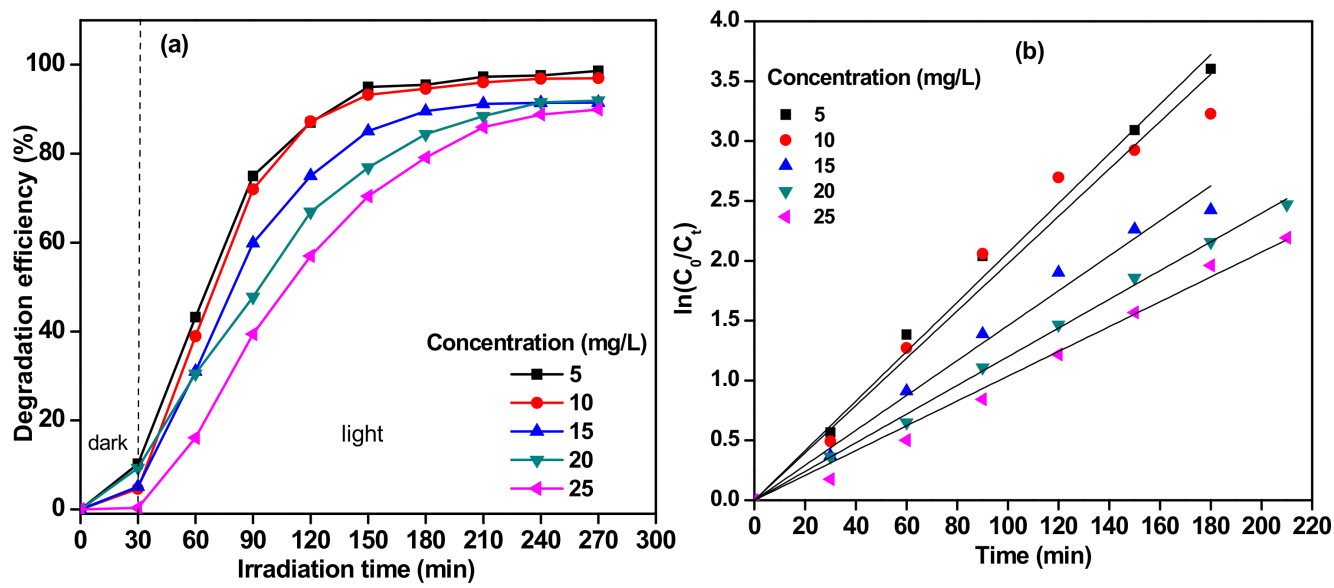

Figure 9. The effect of initial concentration on (a) degradation efficiency and (b) kinetics of MO degradation in the P-AgC (13\%) film photocatalyst (volume of MO: $0.3 \mathrm{~L}$, number of films: 2 films).

Table 3. Kinetic data and amount of MO degraded at different initial concentrations using P-AgC.

\begin{tabular}{|c|c|c|c|c|c|}
\hline $\begin{array}{l}\text { MO Concentration } \\
(\mathrm{mg} / \mathrm{L})\end{array}$ & $\begin{array}{l}\text { Degradation } \\
\text { Efficiency (\%) }\end{array}$ & $\begin{array}{c}\mathbf{k}_{\text {obs }} \\
\left(\mathrm{min}^{-1}\right)\end{array}$ & $\begin{array}{c}\text { Rate } \\
\text { (mg/Lmin) }\end{array}$ & $\begin{array}{c}\text { Amount } \\
\text { Degraded (mg/g) }\end{array}$ & $\begin{array}{l}\text { Correlation } \\
\text { Factor }\left(\mathbf{R}^{2}\right)\end{array}$ \\
\hline 5 & 98.61 & 0.0207 & 0.103 & 3.101 & 0.997 \\
\hline 10 & 96.95 & 0.0198 & 0.198 & 5.952 & 0.989 \\
\hline 15 & 91.45 & 0.0146 & 0.219 & 7.435 & 0.995 \\
\hline 20 & 91.89 & 0.0119 & 0.240 & 11.675 & 0.999 \\
\hline 25 & 89.93 & 0.0104 & 0.259 & 14.336 & 0.996 \\
\hline
\end{tabular}

The effect of $\mathrm{pH}$ in the degradation efficiency of $\mathrm{MO}$ was studied by varying the $\mathrm{pH}$ of $\mathrm{MO}$ solution from 2 to 11 using $1 \mathrm{M}$ of hydrochloric acid $(\mathrm{HCl})$ and sodium hydroxide $(\mathrm{NaOH})$, and the results are depicted in Figure 10a. It can be seen that the photodegradation favored acidic conditions as the degradation efficiency achieved $100 \%$ within $30 \mathrm{~min}$ under irradiation at $\mathrm{pH}$ 2. In acidic conditions, $\mathrm{Ag}_{3} \mathrm{PO}_{4}$ particles dissolved in the solution to form $\mathrm{Ag}^{+}$ions. The presence of $\mathrm{Cl}^{-}$anion leads to the formation of $\mathrm{AgCl} . \mathrm{AgCl}$ is known to possess excellent photocatalytic properties; hence, this $\mathrm{AgCl}$ formation hastens the rate of $\mathrm{MO}$ degradation [32-34]. However, as the initial $\mathrm{pH}$ increased up to 11, the degradation efficiency was depleted. The competitive adsorption between $\mathrm{OH}^{-}$and anionic $\mathrm{MO}$ onto the catalyst surface led to the reduction in degradation efficiency of $\mathrm{MO}$ in alkaline condition. The $\mathrm{pH}_{\mathrm{pzc}}$ of $\mathrm{Ag}_{3} \mathrm{PO}_{4}$ is 6.8, which made its surface charge negative under basic condition [35]. Thus, strong repulsion existed between the anionic $\mathrm{MO}$ and negatively charged $\mathrm{Ag}_{3} \mathrm{PO}_{4}$ surface, resulting in poor degradation activity.
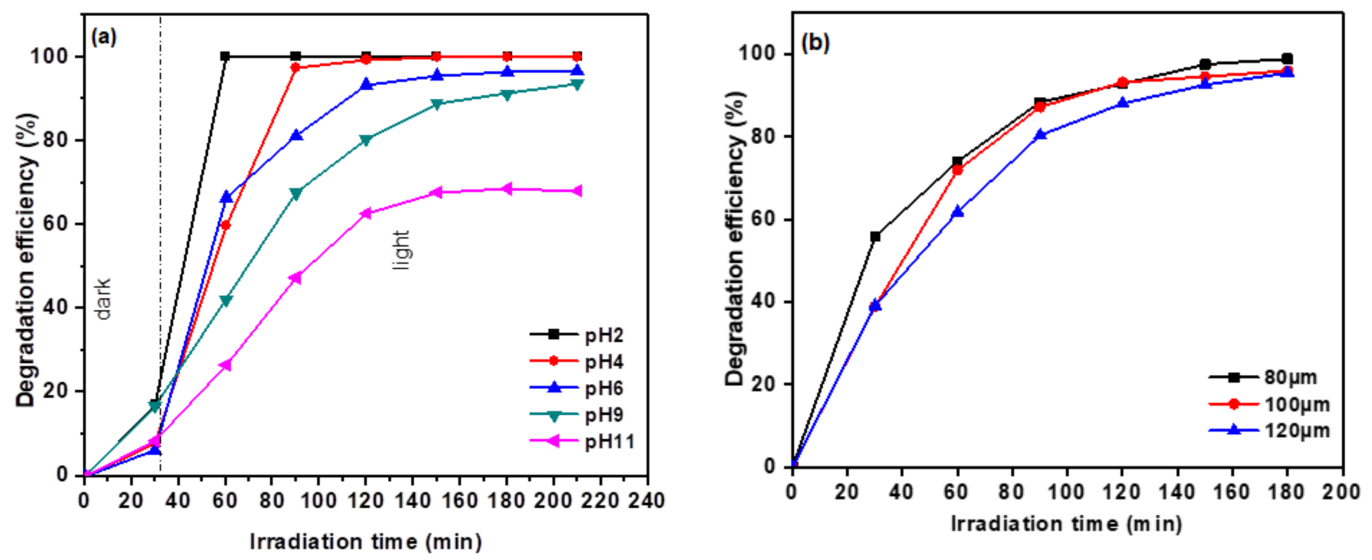

Figure 10. (a). Effect of initial $\mathrm{pH}$ of $\mathrm{MO}$ solution and (b) film thickness on degradation efficiency of P-AgC (13\%) (volume of MO: $0.3 \mathrm{~L}$, number of the film: 2 films, MO concentration: $10 \mathrm{mg} / \mathrm{L}$ ). 
The effect of film thickness on the MO degradation is illustrated in Figure 10b. As the film thickness increased, the light penetration of the top layer of the film decreases, leading to a reduction in the activation of the $\mathrm{Ag}_{3} \mathrm{PO}_{4} / \mathrm{g}-\mathrm{C}_{3} \mathrm{~N}_{4}$ catalyst in the membrane matrix; hence, it reduces the degradation efficiency of the composite film photocatalyst.

To ensure that the MO removal was via the photodegradation process, COD analysis was conducted. As depicted in Figure 11, the COD concentration decreased with increasing reaction time, confirming the degradation of the MO.

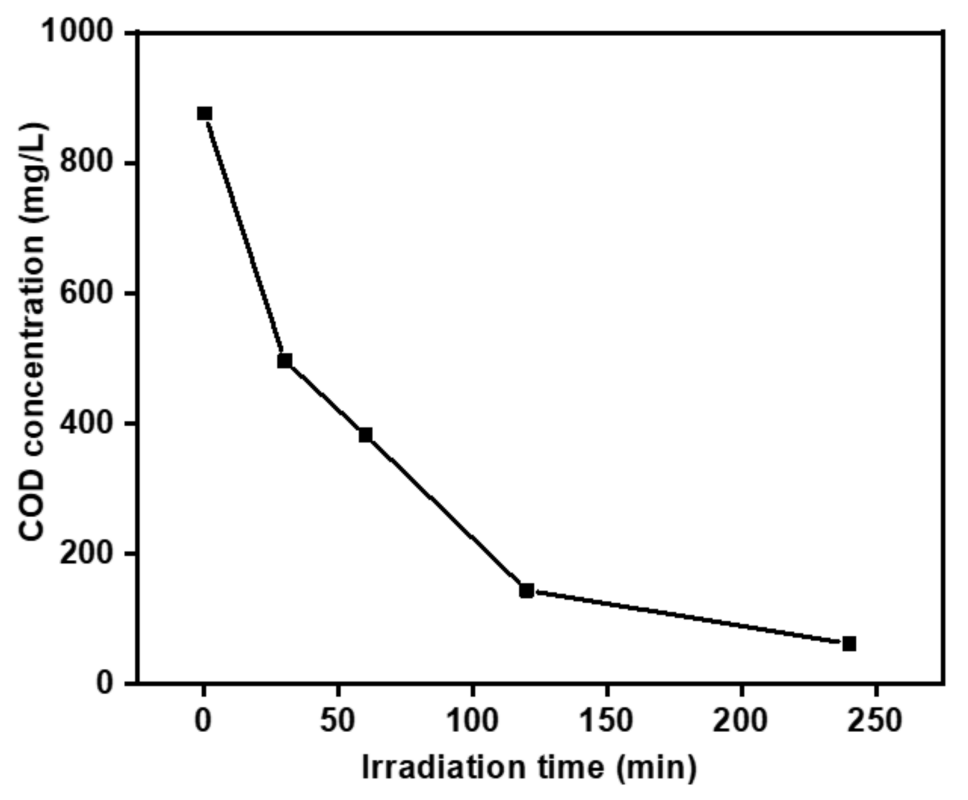

Figure 11. Chemical oxygen demand (COD) removal of P-AgC (13).

\subsection{Reusability of $P-A g C(13 \%)$}

For the reusability study, the photodegradation of $\mathrm{MO}(10 \mathrm{mg} / \mathrm{L})$ by $\mathrm{P}-\mathrm{AgC}(13 \%)$ film was tested at $\mathrm{pH} 6.2$ for $3 \mathrm{~h}$ of irradiation. The catalyst was washed with deionized water and dried before being used in new MO solution for every cycle. After recycling four times, as shown in Figure 12, the degradation efficiency decreased sharply from $96.6 \%$ to $53.5 \%$, which indicates that the P-AgC (13\%) film possesses excellent photocatalytic stability up to three cycles. The high-resolution XPS spectrum of Ag 3d (Figure S2) of the film after six experimental cycles showed dominant peaks of $\mathrm{Ag}^{0}$ at binding energy $368.2 \mathrm{eV}$ and $374.2 \mathrm{eV}$ in $\mathrm{P}-\mathrm{AgC}$ (13) in addition to the peaks attributed to the $\mathrm{Ag}^{+}$at $367.8 \mathrm{eV}$ and $373.6 \mathrm{eV}$. Hence, the decreased in the activity may be due to the formation of Ag particles in the film.

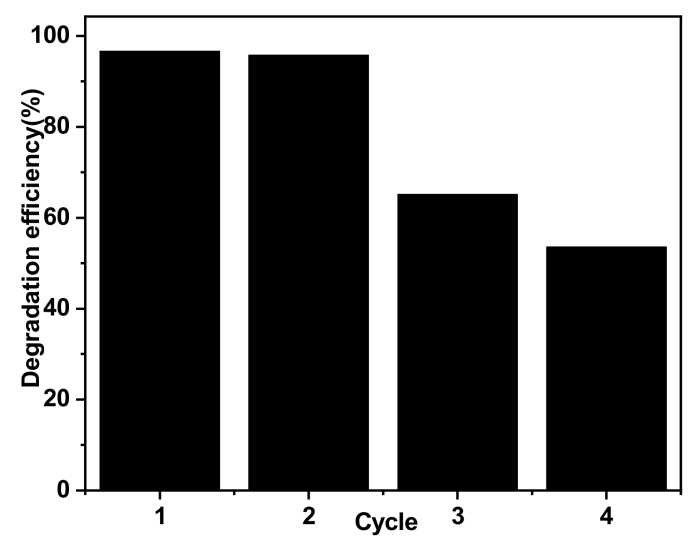

Figure 12. Reusability study of P-AgC 13\%) (volume of MO: $0.3 \mathrm{~L}$, number of the film: 2 films, MO concentration: $10 \mathrm{mg} / \mathrm{L}$ ). 


\subsection{Mechanism of Photodegradation of MO and Effect of Scavengers}

The mechanism for photodegradation of $\mathrm{MO}$ was postulated based on the activation of $\mathrm{Ag}_{3} \mathrm{PO}_{4} / \mathrm{g}-\mathrm{C}_{3} \mathrm{~N}_{4}$ composite photocatalyst by low energy visible light photons to generate electron-hole pairs (Figure 13a). Through a series of reactions between electrons and adsorbed oxygen and between holes and adsorbed water, $\mathrm{OH}$ radicals formed to eventually degrade $\mathrm{MO}$ molecules. The superior photocatalytic activity of $\mathrm{P}-\mathrm{AgC}$ is mainly due to the performance of both $\mathrm{Ag}_{3} \mathrm{PO}_{4}$ and $\mathrm{g}-\mathrm{C}_{3} \mathrm{~N}_{4}$ to form electron-hole pairs for reactive species production in the solution.

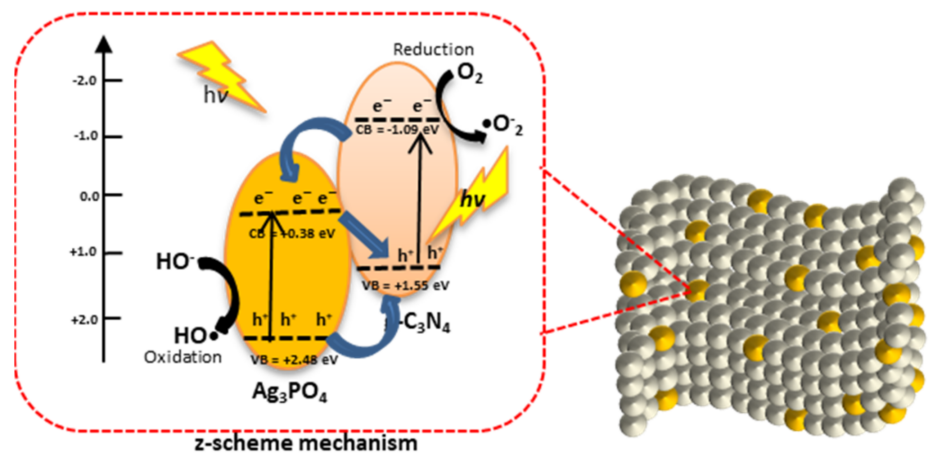

(a)

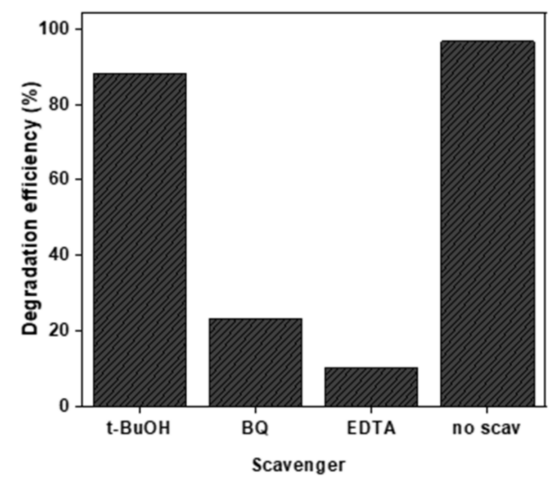

(b)

Figure 13. (a) Plausible mechanism of photodegradation of MO in the P-AgC (13\%) composite film photocatalyst and (b) effect of radical scavengers (tert-butanol, $p$-benzaquinone, sodium EDTA) toward degradation efficiency of MO.

The conduction band $\left(\mathrm{E}_{\mathrm{CB}}\right)$ and valence band $\left(\mathrm{E}_{\mathrm{VB}}\right)$ potentials of the photocatalyst were calculated using Equations (4) and (5), respectively.

$$
\begin{gathered}
\mathrm{E}_{\mathrm{CB}}=\chi-\mathrm{E}^{\mathrm{e}}-0.5 \mathrm{E}_{\mathrm{g}} \\
\mathrm{E}_{\mathrm{VB}}=\mathrm{E}_{\mathrm{CB}}+\mathrm{E}_{\mathrm{g}}
\end{gathered}
$$

where $\mathrm{E}^{\mathrm{e}}$ is the energy of free electrons on the hydrogen scale $(4.5 \mathrm{eV}) ; \mathrm{E}_{\mathrm{g}}$ is the bandgap energy, and $\chi$ is the electronegativity of semiconductor, which was calculated using the following equation:

$$
x=\left[x(A)^{a} x(B)^{b} x(C)^{c}\right]^{1 /(a+b+c)}
$$

where $a, b$, and $c$ are the number of atoms in the compounds.

Based on the $\mathrm{E}_{\mathrm{g}}$ and $\chi$ values of $2.1 \mathrm{eV}$ and $5.93 \mathrm{eV}$, the calculated $\mathrm{E}_{\mathrm{CB}}$ and $\mathrm{E}_{\mathrm{VB}}$ for $\mathrm{Ag}_{3} \mathrm{PO}_{4}$ versus normal hydrogen electrode (NHE) are $+0.38 \mathrm{eV}$ and $+2.48 \mathrm{eV}$, respectively [36,37]. Meanwhile, for the $\mathrm{g}-\mathrm{C}_{3} \mathrm{~N}_{4}$, the $\mathrm{E}_{\mathrm{g}}$ value is $2.65 \mathrm{eV}$ and the $\chi$ values is 4.73 $\mathrm{eV}$; hence, the estimated $\mathrm{E}_{\mathrm{CB}}$ and $\mathrm{E}_{\mathrm{VB}}$ were $-1.09 \mathrm{eV}$ and $+1.55 \mathrm{eV}$, respectively, which agreed with previous research [38-40].

When the visible light irradiated the $\mathrm{Ag}_{3} \mathrm{PO}_{4} / g-\mathrm{C}_{3} \mathrm{~N}_{4}$ composites, the photons would be absorbed by $\mathrm{Ag}_{3} \mathrm{PO}_{4}$ and $\mathrm{g}_{-} \mathrm{C}_{3} \mathrm{~N}_{4}$, generating electron-hole pairs. The photogenerated electrons on the conduction band (CB) of g- $\mathrm{C}_{3} \mathrm{~N}_{4}$ react with adsorbed $\mathrm{O}_{2}$ to form $\bullet \mathrm{O}_{2}{ }^{-}$radicals, because $\mathrm{CB}$ of $\mathrm{g}-\mathrm{C}_{3} \mathrm{~N}_{4}$ is more negative than the potential of $\mathrm{O}_{2} / \bullet \mathrm{O}_{2}{ }^{-}\left(\mathrm{E}^{\mathrm{O}}\left(\mathrm{O}_{2} / \bullet \mathrm{O}_{2}{ }^{-}\right)=-0.33 \mathrm{eV} / \mathrm{NHE}\right)$ [41]. Since the $\mathrm{CB}$ edge potential of $\mathrm{Ag}_{3} \mathrm{PO}_{4}(+0.38 \mathrm{eV})$ is more positive than the standard redox potential of $\mathrm{O}_{2} / \bullet \mathrm{O}_{2}{ }^{-}, \mathrm{Ag}_{3} \mathrm{PO}_{4}$ cannot reduce $\mathrm{O}_{2}$ to $\bullet \mathrm{O}_{2}{ }^{-}$. However, the electrons in the $\mathrm{CB}$ of $\mathrm{Ag}_{3} \mathrm{PO}_{4}$ can be transferred to adsorbed oxygen molecules to produce $\mathrm{H}_{2} \mathrm{O}_{2}$, because the $\mathrm{CB}$ of $\mathrm{Ag}_{3} \mathrm{PO}_{4}$ is more negative than $\mathrm{E}^{\mathrm{o}}\left(\mathrm{O}_{2} / \mathrm{H}_{2} \mathrm{O}_{2}=+0.682 \mathrm{eV}\right.$ vs. NHE). The produced $\mathrm{H}_{2} \mathrm{O}_{2}$ molecules react with electrons to produce $\bullet \mathrm{OH}$ radicals [37]. Through the $\mathrm{z}$-scheme mechanism, the electrons can also be transferred to the valence band (VB) of the $g-\mathrm{C}_{3} \mathrm{~N}_{4}$ [42]. On the other hand, the holes in the valence band of $\mathrm{Ag}_{3} \mathrm{PO}_{4}$ can oxidize the pollutant directly, since the VB potential of $\mathrm{Ag}_{3} \mathrm{PO}_{4}$ is more positive than the $\mathrm{E}^{\mathrm{o}}\left(\mathrm{OH}^{-} / \bullet \mathrm{OH}=+2.4 \mathrm{eV}\right)$.

To study the main reactive species involved in the photodegradation of $\mathrm{MO}$, tertbutanol, p-benzoquinone, and sodium EDTA were used as a trapper for hydroxyl radicals 
$(\bullet \mathrm{OH})$, superoxide anion radicals $\left(\bullet \mathrm{O}_{2}^{-}\right)$, and holes $\left(\mathrm{h}^{+}\right)$, respectively, in the reaction system, and the results are shown in Figure 13b. When p-benzoquinone and sodium EDTA were used, the degradation efficiency declined to $23 \%$ and $10 \%$, respectively. It can be concluded that $\bullet \mathrm{O}_{2}{ }^{-}$and $\mathrm{h}^{+}$were the dominant radical species involved in the degradation of MO.

\section{Conclusions}

A novel PES- $\mathrm{Ag}_{3} \mathrm{PO}_{4} / \mathrm{g}-\mathrm{C}_{3} \mathrm{~N}_{4}$ was successfully fabricated by the phase inversion technique. The incorporation of $\mathrm{Ag}_{3} \mathrm{PO}_{4} / \mathrm{g}-\mathrm{C}_{3} \mathrm{~N}_{4}$ into the PES matrix widened the finger-like microvoid structure and formed a bottle-neck structure. The film hydrophilicity, surface roughness, and porosity were also enhanced significantly. The dye degradation experiment showed that $13(\mathrm{wt} \%)$ is the optimum amount of the $\mathrm{Ag}_{3} \mathrm{PO}_{4} / \mathrm{g}-\mathrm{C}_{3} \mathrm{~N}_{4}$ composite to be loaded into the PES matrix, which resulted in the highest photocatalytic activity. The PES$\mathrm{Ag}_{3} \mathrm{PO}_{4} / \mathrm{g}-\mathrm{C}_{3} \mathrm{~N}_{4}$ could be used up to three cycles before the performance was reduced to half. The $\bullet \mathrm{O}_{2}{ }^{-}$and $\mathrm{h}^{+}$were the dominant species in the degradation of MO.

Supplementary Materials: The following are available online at https:/ /www.mdpi.com/article/10.3390/ polym13111746/s1.

Author Contributions: Conceptualization, A.H.A., Z.Z., H.N.L.; methodology, A.H.A., Z.Z., H.N.L.; validation, A.H.A., Z.Z., H.N.L.; formal analysis, H.M.M., A.H.A.; investigation, H.M.M.; writing—original draft preparation, H.M.M.; writing—review and editing, A.H.A., and Z.Z.; supervision, A.H.A., Z.Z., H.N.L.; project administration, A.H.A.; funding acquisition, A.H.A. All authors have read and agreed to the published version of the manuscript.

Funding: This research was funded by Ministry of Higher Education, Malaysia, under FRGS-MRSA 2015 Research Grant.

Institutional Review Board Statement: Not applicable.

Informed Consent Statement: Not applicable.

Data Availability Statement: The data presented in this study are available on request from the corresponding author.

Acknowledgments: We acknowledged the Universiti Putra Malaysia, Universiti Kebangsaan Malaysia (UKM) and Universiti Teknologi Mara (UiTM) for the services and facilities to carry out the laboratory work.

Conflicts of Interest: The authors declare that there are no conflict of interest associated with this publication.

\section{References}

1. Kumar, J.; Bansal, A. A comparative study of immobilization techniques for photocatalytic degradation of Rhodamine B using nanoparticles of titanium dioxide. Water Air Soil Pollut. 2013, 224, 1-11. [CrossRef]

2. Yang, T.; Yu, D.; Wang, D.; Yang, T.; Li, Z.; Wu, M.; Petru, M.; Crittenden, J. Accelerating Fe(III)/Fe(II) cycle via Fe(II) substitution for enhancing Fenton-like performance of Fe-MOFs. Appl. Catal. B Environ. 2021, 286, 119859. [CrossRef]

3. Yu, D.; Li, L.; Wu, M.; Crittenden, J.C. Enhanced photocatalytic ozonation of organic pollutants using an iron-based metal-organic framework. Appl. Catal. B Environ. 2019, 251, 66-75. [CrossRef]

4. Idris, A.M.; Shinger, M.I.; Qin, D.D.; Baballa, H.; Lu, X. An in-situ anion exchange method synthesized of $\mathrm{Ag}_{3} \mathrm{PO}_{4}$ functionalized with $\mathrm{Fe}_{3} \mathrm{O}_{4}$ and $\mathrm{AgI}$ for photocatalytic degradation of methyl orange under visible light irradiation. IJMSA 2014, 3, 303-308. [CrossRef]

5. Zhou, L.; Zhang, W.; Chen, L.; Deng, H. Z-scheme mechanism of photogenerated carriers for hybrid photocatalyst $\mathrm{Ag}_{3} \mathrm{PO}_{4} / \mathrm{g}$ $\mathrm{C}_{3} \mathrm{~N}_{4}$ in degradation of sulfamethoxazole. J. Colloid Interface Sci. 2017, 487, 410-417. [CrossRef] [PubMed]

6. You, M.; Pan, J.; Chi, C.; Wang, B.; Zhao, W.; Song, C.; Zheng, Y.; Li, C. The visible light hydrogen production of the Z-Scheme $\mathrm{Ag}_{3} \mathrm{PO}_{4} / \mathrm{Ag} / \mathrm{g}-\mathrm{C}_{3} \mathrm{~N}_{4}$ nanosheets composites. J. Mater. Sci. 2018, 53, 1978-1986. [CrossRef]

7. Cui, X.; Tian, L.; Xian, X.; Tang, H.; Yang, X. Solar photocatalytic water oxidation over $\mathrm{Ag}_{3} \mathrm{PO}_{4} / \mathrm{g}-\mathrm{C}_{3} \mathrm{~N}_{4}$ composite materials mediated by metallic Ag and graphene. Appl. Surf. Sci. 2018, 430, 108-115. [CrossRef]

8. Meng, S.; Ning, X.; Zhang, T.; Chen, S.-F.; Fu, X. What is the transfer mechanism of photogenerated carriers for the nanocomposite photocatalyst $\mathrm{Ag}_{3} \mathrm{PO}_{4} / \mathrm{g}-\mathrm{C}_{3} \mathrm{~N}_{4}$, band-band transfer or a direct Z-scheme? Phys. Chem. Chem. Phys. 2015, 17, 11577-11585. [CrossRef] 
9. Shi, F.; Ma, Y.; Ma, J.; Wang, P.; Sun, W. Preparation and characterization of $\mathrm{PVDF} / \mathrm{TiO}_{2}$ hybrid membranes with different dosage of nano-TiO 2 . J. Memb. Sci. 2012, 389, 522-531. [CrossRef]

10. Moslehyani, A.; Ismail, A.F.; Othman, M.H.D.; Matsuura, T. Design and performance study of hybrid photocatalytic reactorPVDF/MWCNT nanocomposite membrane system for treatment of petroleum refinery wastewater. Desalination 2015, 363, 99-111. [CrossRef]

11. Cui, Y.; Yang, L.; Meng, M.; Zhang, Q.; Li, B.; Wu, Y.; Zhang, Y.; Lang, J.; Li, C. Facile preparation of antifouling g-C $\mathrm{N}_{4} / \mathrm{Ag}_{3} \mathrm{PO}_{4}$ nanocomposite photocatalytic polyvinylidene fluoride membranes for effective removal of rhodamine B. Korean J. Chem. Eng. 2019, 36, 236-247. [CrossRef]

12. Kuvarega, A.T.; Khumalo, N.; Dlamini, D.; Mamba, B.B. Polysulfone/N,Pd co-doped $\mathrm{TiO}_{2}$ composite membranes for photocatalytic dye degradation. Sep. Purif. Technol. 2018, 191, 122-133. [CrossRef]

13. Chen, X.; Zhou, W.; Chen, Z.; Yao, L. Study of the Photocatalytic Property of Polysulfone Membrane Incorporating TiO 2 Nanoparticles. J. Mol. Eng. Mater. 2017, 5, 1750005. [CrossRef]

14. Adlan, Z.; Hir, M.; Moradihamedani, P.; Abdullah, A.H.; Mohamed, M.A. Immobilization of $\mathrm{TiO}_{2}$ into polyethersulfone matrix as hybrid film photocatalyst for effective degradation of methyl orange dye. Mater. Sci. Semicond. Process. 2017, 57, 157-165.

15. Mohd Hir, Z.; Abdullah, A.; Zainal, Z.; Lim, H. Photoactive Hybrid Film Photocatalyst of Polyethersulfone-ZnO for the Degradation of Methyl Orange Dye: Kinetic Study and Operational Parameters. Catalysts 2017, 7, 313. [CrossRef]

16. Rajeswari, A.; Vismaiya, S.; Pius, A. Preparation, characterization of nano ZnO-blended cellulose acetate-polyurethane membrane for photocatalytic degradation of dyes from water. Chem. Eng. J. 2017, 313, 928-937. [CrossRef]

17. Kanjwal, M.A.; Barakat, N.A.M.; Chronakis, I.S. Photocatalytic degradation of dairy effluent using $\mathrm{AgTiO}_{2}$ nanostructures/polyurethane nanofiber membrane. Ceram. Int. 2015, 41, 9615-9621. [CrossRef]

18. Saeed, K.; Khan, I.; Shah, T.; Park, S.Y. Synthesis, characterization and photocatalytic activity of silver nanoparticles/amidoximemodified polyacrylonitrile nanofibers. Fibers Polym. 2015, 16, 1870-1875. [CrossRef]

19. Luo, Q.; Yang, X.; Zhao, X.; Wang, D.; Yin, R.; Li, X.; An, J. Facile preparation of well-dispersed ZnO/cyclized polyacrylonitrile nanocomposites with highly enhanced visible-light photocatalytic activity. Appl. Catal. B Environ. 2017, 204, 304-315. [CrossRef]

20. Yu, D.; Bai, J.; Liang, H.; Wang, J.; Li, C. A new fabrication of $\mathrm{AgX}\left(\mathrm{X}=\mathrm{Br}\right.$, I)- $\mathrm{TiO}_{2}$ nanoparticles immobilized on polyacrylonitrile (PAN) nanofibers with high photocatalytic activity and renewable property. RSC Adv. 2015, 5, 91457-91465. [CrossRef]

21. Mozia, S.; Darowna, D.; Wróbel, R.; Morawski, A.W. A study on the stability of polyethersulfone ultrafiltration membranes in a photocatalytic membrane reactor. J. Memb. Sci. 2015, 495, 176-186. [CrossRef]

22. Fischer, K.; Kühnert, M.; Gläser, R.; Schulze, A. Photocatalytic degradation and toxicity evaluation of diclofenac by nanotubular titanium dioxide-PES membrane in a static and continuous setup. RSC Adv. 2015, 5, 16340-16348. [CrossRef]

23. Fischer, K.; Gläser, R.; Schulze, A. Nanoneedle and nanotubular titanium dioxide-PES mixed matrix membrane for photocatalysis. Appl. Catal. B Environ. 2014, 160-161, 456-464. [CrossRef]

24. Zhang, M.; Liu, Z.; Gao, Y.; Shu, L. Ag modified g- $\mathrm{C}_{3} \mathrm{~N}_{4}$ composite entrapped PES UF membrane with visible-light-driven photocatalytic antifouling performance. RSC Adv. 2017, 7, 42919-42928. [CrossRef]

25. Ghalamchi, L.; Aber, S.; Vatanpour, V.; Kian, M. A novel antibacterial mixed matrixed PES membrane fabricated from embedding aminated $\mathrm{Ag}_{3} \mathrm{PO}_{4} / \mathrm{g}-\mathrm{C}_{3} \mathrm{~N}_{4}$ nanocomposite for use in the membrane bioreactor. J. Ind. Eng. Chem. 2019, 70, 412-426. [CrossRef]

26. Zhang, W.; Zhou, L.; Deng, H. Ag modified g- $\mathrm{C}_{3} \mathrm{~N}_{4}$ composites with enhanced visible-light photocatalytic activity for diclofenac degradation. J. Mol. Catal. A Chem. 2016, 423, 270-276. [CrossRef]

27. Zheng, R.; Lin, L.; Xie, J.; Zhu, Y.; Xie, Y. State of doped phosphorus and its influence on the physicochemical and photocatalytic properties of P-doped titania. J. Phys. Chem. C 2008, 112, 15502-15509. [CrossRef]

28. Yang, X.; Chen, Z.; Xu, J.; Tang, H.; Chen, K.; Jiang, Y. Tuning the Morphology of g- $\mathrm{C}_{3} \mathrm{~N}_{4}$ for Improvement of Z-Scheme Photocatalytic Water Oxidation. ACS Appl. Mater. Interfaces 2015, 7, 15285-15293. [CrossRef]

29. Liu, M.; Xu, K.; Zhu, J.; Yue, X.; Ji, Z.; Kong, L.; Miao, X.; Zhou, H.; Zhu, G.; Shah, S.A.; et al. Nitrogen-doped carbon dots decorated on $\mathrm{g}_{-} \mathrm{C}_{3} \mathrm{~N}_{4} / \mathrm{Ag}_{3} \mathrm{PO}_{4}$ photocatalyst with improved visible light photocatalytic activity and mechanism insight. Appl. Catal. B Environ. 2018, 227, 459-469. [CrossRef]

30. Koe, W.S.; Lee, J.W.; Chong, W.C.; Pang, Y.L.; Sim, L.C. An overview of photocatalytic degradation: Photocatalysts, mechanisms, and development of photocatalytic membrane. Environ. Sci. Pollut. Res. 2020, 27, 2522-2565. [CrossRef]

31. Das, L.; Barodia, S.K.; Sengupta, S.; Basu, J.K. Aqueous degradation kinetics of pharmaceutical drug diclofenac by photocatalysis using nanostructured titania-zirconia composite catalyst. Int. J. Environ. Sci. Technol. 2015, 12, 317-326. [CrossRef]

32. Yao, X.; Liu, X.; Zhu, D.; Zhao, C.; Lu, L. Synthesis of cube-like Ag/ AgCl plasmonic photocatalyst with enhanced visible light photocatalytic activity. Catal. Commun. 2014, 59, 151-155. [CrossRef]

33. Li, H.; Li, C.; Li, N.; Zhu, L.; Zhuo, Y.; Xiong, D. One-step synthesis of novel Ag/AgCl-glass with remarkably stable photocatalytic activity. J. Non. Cryst. Solids 2019, 506, 21-27. [CrossRef]

34. Asadzadeh-Khaneghah, S.; Habibi-Yangjeh, A.; Abedi, M. Decoration of carbon dots and AgCl over g- $\mathrm{C}_{3} \mathrm{~N}_{4}$ nanosheets: Novel photocatalysts with substantially improved activity under visible light. Sep. Purif. Technol. 2018, 199, 64-77. [CrossRef]

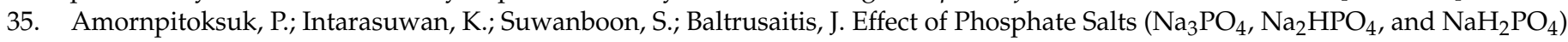
on $\mathrm{Ag}_{3} \mathrm{PO}_{4}$ Morphology for Photocatalytic Dye Degradation under Visible Light and Toxicity of the Degraded Dye Products. Ind. Eng. Chem. Res. 2013, 52, 17369-17375. [CrossRef] 
36. Cui, X.; Zheng, Y.F.; Zhou, H.; Yin, H.Y.; Song, X.C. The effect of synthesis temperature on the morphologies and visible light photocatalytic performance of $\mathrm{Ag}_{3} \mathrm{PO}_{4}$. J. Taiwan Inst. Chem. Eng. 2016, 60, 328-334. [CrossRef]

37. Mousavi, M.; Habibi-Yangjeh, A.; Abitorabi, M. Fabrication of novel magnetically separable nanocomposites using graphitic carbon nitride, silver phosphate and silver chloride and their applications in photocatalytic removal of different pollutants using visible-light irradiation. J. Colloid Interface Sci. 2016, 480, 218-231. [CrossRef] [PubMed]

38. Cui, L.; Ding, X.; Wang, Y.; Shi, H.; Huang, L.; Zuo, Y.; Kang, S. Facile preparation of Z-scheme $\mathrm{WO}_{3} / \mathrm{g}-\mathrm{C}_{3} \mathrm{~N}_{4}$ composite photocatalyst with enhanced photocatalytic performance under visible light. Appl. Surf. Sci. 2017, 391, 202-210. [CrossRef]

39. Liu, J. Origin of High Photocatalytic Efficiency in Monolayer g- $\mathrm{C}_{3} \mathrm{~N}_{4} / \mathrm{CdS}$ Heterostructure: A Hybrid DFT Study. J. Phys. Chem. C 2015, 119, 28417-28423. [CrossRef]

40. Meng, J.; Pei, J.; He, Z.; Wu, S.; Lin, Q.; Wei, X.; Li, J.; Zhang, Z. Facile synthesis of g- $\mathrm{C}_{3} \mathrm{~N}_{4}$ nanosheets loaded with $\mathrm{WO}_{3}$ nanoparticles with enhanced photocatalytic performance under visible light irradiation. RSC Adv. 2017, 7, 24097-24104. [CrossRef]

41. Xu, H.; Zhao, H.; Song, Y.; Yan, W.; Xu, Y.; Li, H.; Huang, L.; Yin, S.; Li, Y.; Zhang, Q.; et al. g-C $\mathrm{C}_{3} \mathrm{~N}_{4} / \mathrm{Ag}_{3} \mathrm{PO}_{4}$ composites with synergistic effect for increased photocatalytic activity under the visible light irradiation. Mater. Sci. Semicond. Process. 2015, 39, 726-734. [CrossRef]

42. Katsumata, H.; Sakai, T.; Suzuki, T.; Kaneco, S. Highly Efficient Photocatalytic Activity of g- $\mathrm{C}_{3} \mathrm{~N}_{4} / \mathrm{Ag}_{3} \mathrm{PO}_{4} \mathrm{Hybrid}_{\mathrm{Photocatalysts}}$ through Z-Scheme Photocatalytic Mechanism under Visible Light. Ind. Eng. Chem. Res. 2014, 53, 8018-8025. [CrossRef] 